\title{
Análise da Interação entre o Leitor e o Livro Didático: Um Estudo nos Livros de Ciências dos Anos Iniciais
}

\author{
Analysis of the Interaction between Reader and Textbook: A Study with \\ Elementary Science Textbooks
}

Palavras-chave Resumo O objetivo deste estudo foi identificar as perspectivas de Tecnologias Digitais interação entre o leitor e o livro didático por meio das TDIC e, para isso, de Informação foram analisados os livros didáticos (LD) de Ciências dos anos iniciais e Comunicação do Ensino Fundamental aprovados no PNLD de 2019. A investigação (TDIC); Plano foi desenvolvida a partir de uma análise documental e bibliográfica que, Nacional do Livro Didático (PNLD); Ensino de Ciências; Livro Didático de Ciências. a partir das 14 coleções aprovadas, distribuídas em 70 livros didáticos, possibilitou a criação de seis categorias de análise que expressam as formas de inserção das TDIC nos materiais estudados considerandose a frequência com que referências às tecnologias emergem nos textos. Nota-se a presença de seis categorias que evidenciam desde a disponibilidade de links para busca de informações e realização de atividades externas ao livro até a divulgação de imagens relacionadas às TDIC. No movimento de desvelamento destas categorias, propomos que existem dois tipos de perspectivas de interação entre o leitor e os livros didáticos de Ciências analisados. A primeira forma de interação se dá por meio de imagens e textos que direcionam para o próprio livro. A segunda forma de interação refere-se ao direcionamento para que o estudante busque informações externas ao livro didático, no sentido de complementar a formação de caráter científico. 
Keywords Abstract The objective of this study was to identify the perspectives of Digital interaction between reader and textbooks through Digital Information Information and and Communication Technologies (DICTs). To this end, we analyzed Communication elementary science textbooks approved in Brazil under the National

Technologies Textbook Plan of 2019 documentary Consisting of documental and

(DICT); bibliographic analysis of the 14 approved collections distributed in National Textbook 70 textbooks, this documentary research prepared for the creation Plan (PNLD); of six categories of analysis that reflect the ways of using DICT in Teaching of Science; the materials studied, considering the frequency of references to Science Textbooks. technologies in the texts. Six categories have been identified, ranging from the availability of links to theory and practice external to the textbook, to dissemination of images related to DICT. In the unveiling of these categories, we propose that there are two types of perspectives of interaction between the reader and the Science textbooks analyzed. The first form of interaction is through images and texts that point to the book itself. The second form of interaction refers to directing students to seek information outside the textbook, in order to complement the scientific formation.

\section{Introdução}

O Programa Nacional do Livro e do Material Didático (PNLD) unificou as ações de aquisição de livro didático no Brasil, contemplando a distribuição de livros e materiais didáticos à educação básica para atendimento de suas distintas etapas e a seleção desses materiais se estrutura por meio de editais. Segundo o Guia do Livro Didático - GLD (MEC, 2019) esta é uma das maiores ações governamentais para distribuição de livros didáticos do mundo e, dessa forma, torna-se importante analisar e discutir suas contribuições para o contexto educacional, considerando-se o investimento governamental que para o PNLD 2019 foi de R \$1.102.571.912,18 (um bilhão, cento e dois milhões, quinhentos e setenta e um mil, novecentos e doze reais e dezoito centavos) (MEC, 2020). Para os anos iniciais do Ensino Fundamental, o investimento total para as tiragens fora contabilizado no valor total de $\mathrm{R} \$$ 80.743.804 (oitenta milhões, setecentos e quarenta e três mil e oitocentos e quatro reais).

Ao tratarmos de LD de Ciências para os anos iniciais do Ensino Fundamental é importante destacar diversas influências que, nos últimos anos, ocasionaram a necessidade de mudanças e implementações nestes materiais. Nesse sentido, as questões relacionadas às tecnologias que se fazem presentes no contexto educacional, se constituem como elementos a serem inseridos nos LD em uma perspectiva de atualização destes materiais. Entendemos então que com o desenvolvimento de tecnologias educacionais, o LD não será descartado, mas passará a incorporar as tecnologias, pensamento apoiado por Moreira e 
Rodrigues (2014, p. 64) quando dizem que "ao invés de o LD sair de cena ele incorpora as TICs como mais um saber a ser didatizado".

Por conseguinte, não podemos nos esquivar da tendência da utilização da tecnologia no ensino, tendo em vista a era da informação que nos cerca. Nesse contexto, dentre essas tecnologias, destacaremos as Tecnologias Digitais da Informação e Comunicação (TDIC). Essa tecnologia segundo Costa, Duqueviz e Pedroza (2015, p. 604) se refere "a um computador, tablet, celular, smartphone e qualquer outro dispositivo que permita a navegação na internet”. Dessarte, as TDIC trazem aspectos importantes para o contexto educacional, o que comunga com a ideia proposta por Kenski (2003) quando discorre sobre as possibilidades interativas que as novas tecnologias podem trazer, influenciando até mesmo nas concepções e nas formas de se ensinar e aprender.

A partir de tais conjecturas, salientamos que investigações que se debrucem sobre o livro didático são de suma importância ao considerarmos sua presença maciça nas escolas, tanto para uso do professor quanto dos alunos, além dos altos valores destinados ao PNLD. Dessa forma, focar no ensino de ciências é significante pois este componente curricular é base para outros mais específicos e complexos no decorrer do ensino básico, como biologia, química e física. E dentre as nuances possíveis de estudo a partir do livro didático, as perspectivas de interação entre o leitor e o LD são questões a serem postas em evidência, pois estudos mais específicos acerca de livro didático de ciências, segundo Rosa e Mohr (2016), são relativamente recentes pois 75\% das pesquisas ocorreram a partir dos anos 90.

Considerando-se a amplitude do PNLD, o investimento governamental neste programa, a importância do livro de ciências como basilar nos processos de alfabetização científica dos estudantes e as possibilidades pedagógicas do LD em termos de interação com os leitores, o recorte investigativo aqui tratado diz respeito aos livros didáticos de Ciências dos anos iniciais do Ensino Fundamental aprovados no PNLD de 2019, a partir dos quais esta investigação objetivou identificar e analisar as perspectivas de interação entre o leitor e o livro didático. No sentido de buscar elementos que configurem tais processos de interação, utilizamos como temática as abordagens relacionadas às TDIC.

\section{A Interação entre o Leitor e o LD: Questões Gerais em Foco}

Pesquisas sobre o livro didático estão em progressivo aumento no Brasil nas últimas décadas, pois em uma pesquisa no Catálogo de Teses e Dissertações da Capes (Brasil, 2020), utilizando do termo de busca "livro didático" se visualizam quase vinte e cinco mil publicações, sendo que comparativamente o ano de 2019 teve 53 vezes mais publicações relativas ao livro didático que no ano de 1990, e dessa forma, já se confirma o aumento de investigações que têm como foco o LD. Ainda nessa pesquisa verificouse que a média anual de publicações sobre o livro didático entre os anos de 2015 a 2019, se mantem acima de duas mil a cada ano, ultrapassando qualquer média de outro quinquênio desse período, demonstrando dessa forma, a importância dessa temática nos dias atuais. 
É relevante destacarmos que as problemáticas atuais de pesquisa sobre o livro didático estão ligadas a questões como a sua maciça presença do LD nas escolas, como também os altos valores destinados ao PNLD, além de estudos mais específicos de cada componente curricular. Nesse sentido, Garcia (2012) observa que nos livros de Ciências do Ensino Fundamental há uma tradição nas pesquisas que o tomam como objeto de estudo a partir do enfoque no conteúdo e equívocos conceituais presentes no livro. No entanto, há lacunas na literatura no que concerne à investigações que busquem compreender as interações entre os sujeitos escolares os livros didáticos tendo como foco as TDIC. Dessa forma, salientamos que o foco apresentado no artigo em tela não é propriamente o conteúdo presente no livro e nem mesmo o leitor individualmente, mas a abordagem na qual se constrói a comunicação entre eles. Destacamos que tal enfoque, por não ser discutido na literatura, foi objeto de análise da tese de doutoramento que dá origem às discussões apresentadas neste texto.

Desse modo, o estudo sobre a interação entre o leitor e o LD é corroborado sob três aspectos gerais: necessidade das relações entre o leitor e os objetos da cultura escolar; comunicação entre o autor e o leitor; e a própria comunicação dialógica presente no livro didático. No primeiro aspecto citamos Leite, Garcia e Rocha (2011, p. 11741) quando expressam que "muito do que se aprende e ensina numa sala de aula depende das relações que os sujeitos estabelecem com seus pares e com os objetos da cultura escolar presentes em sala de aula". Ao considerarmos o LD como objeto da cultura escolar (LD) e buscarmos entender como este estabelece relações com o sujeito (leitor), o universo de conhecimentos sobre os processos de ensino e aprendizagem pode ser ampliado. Acerca do segundo aspecto, Fellini (2012) disserta que as formas de interação entre o livro e o aluno (leitor) podem ser analisadas por meio das propostas presentes nele, pois é a partir daí que o autor fala diretamente com o leitor, apresentando sua intencionalidade do aprender-ensinar e assim "dando as diretrizes para as interações no uso do livro" (p. 44). Considerando tal aspecto, compreendemos que a interação entre o leitor e livro didático traz impressa interesses e valores que se configuram a partir de balizamentos estabelecidos por meio de diretrizes, como é o caso do edital do PNLD. O terceiro ponto trata da própria comunicação dialógica presente nos textos. Nesse contexto, Silva et al. (2017) expressam que o estilo dialógico do material didático deve garantir uma interação efetiva entre o ele o seu leitor, como se o próprio professor estivesse ao seu lado, ouvindo-o e conversando com ele através do livro, em um cenário no qual esse diálogo entre o leitor e o LD esteja sempre em contínua construção

Tendo em vista os apontamentos explicitados, nos quais se evidencia a relevância da interação que se constitui como elemento presente no $\mathrm{LD}$, enfatizamos que o estudo das perspectivas de interação entre o leitor e o livro didático, tendo a inserção das tecnologias como enfoque de análise, é um caminho ainda pouco explorado como viés investigativo no âmbito da área de Ensino de Ciências. Isso posto, nos propomos, a partir da socialização de nossa pesquisa, a contribuir com a referida área para desvelar um recorte do universo delimitado pelas relações pela interação entre o leitor, o LD e a inserção das tecnologias nestes textos. 


\section{Livro Didático, Ensino de Ciências e a TDIC}

Ao se dissertar sobre livro didático, ensino de ciências e TDIC, podemos discorrer independentemente acerca deles, no entanto, de outro modo podemos relacioná-los para, a partir daí, conhecer suas permeabilidades e assim, os termos conectados e suas interrelações. Dessa forma, essa pesquisa vai discorrer um pouco sobre esses três temas de forma relacional. No Brasil, o currículo base para o ensino de Ciências nos anos iniciais do Ensino Fundamental está fortemente ligado ao livro didático que é distribuído pelo governo. E assim, como dito por Baganha e Garcia (2011), a sequência estabelecida pelo livro didático influencia diretamente na rotina do professor que o utiliza como norteador de seu planejamento de aula. Dessa forma, essa política pública deve estar sob uma rigorosa avaliação para que o resultado seja um livro de qualidade, excluindo-se erros conceituais e metodológicos, além de qualquer orientação de natureza discriminatória ou preconceituosa.

O livro didático de Ciências deve observar os aspectos lúdicos e investigativos tendo em vista o seu público-alvo, além do que também não pode deixar delado o universo tecnológico que nos circunda. É importante que o LD se configure também como um elemento importante no sentido de despertar nos alunos o interesse pela Ciência desde o início das atividades escolares. Com vistas a isso, o MEC ao disponibilizar a BNCC (MEC, 2018a) em sua versão final, sugere a estrutura curricular nos livros didáticos de Ciências a partir das grandes unidades temáticas de: matéria e energia; vida e evolução; e, por fim, terra e o universo. Essas unidades deverão ser adequadas de acordo com o progresso nos anos escolares pelo aluno, além do que, o ensino pelo professor de Ciências deve levar em consideração a contextualização local e as particularidades em que está inserida a escola.

O uso de TDIC no ensino de Ciências está disposto na BNCC (MEC, 2018a) quando se trata das competências específicas de Ciências da Natureza para o Ensino Fundamental que destacam esse uso como fonte de comunicação, acesso e disseminação das informações com foco a produzir conhecimento além de resolver problemas das Ciências da Natureza de forma crítica, significativa, reflexiva e ética. Ao discutirmos as possibilidades estabelecidas entre as TDIC e o ensino de Ciências, torna-se importante explicitar a importância e o papel deste ensino na elaboração de significados pelos estudantes que permitam interpretar o mundo a sua volta a partir da compreensão de saberes científicos. Nesse sentido, compartilhamos a perspectiva de Silva e Kalhil (2018) ao argumentarem que as tecnologias digitais podem ter um papel relevante de ferramenta de apoio para o ensino de ciências ao trazer um novo tipo de linguagem alinhado aos tempos atuais.

Dessa forma, o modelo a ser utilizado com as TDIC para a construção do saber precisa se pautar na participação, investigação e envolvimento com os alunos. Ao se discutir sobre a utilização das tecnologias em sala de aula, torna-se importante ressaltar que este uso, por si só, não significa aprendizagem ou conhecimento e que é necessário fugir de modismos, mas as TDIC no contexto do ensino de Ciências podem 
ampliar estratégias de abordagem de conceitos inserindo o ambiente escolar em um mundo já vivido pelos estudantes, tal pensamento é reafirmado no Guia de Tecnologias Educacionais (MEC, 2008). A vista disso, ao se pensar as TDIC para abordagem de Ciências para o Ensino Fundamental é mister entendê-las como ferramentas didáticas que associam as tecnologias à ludicidade, fato que pode possibilitar o despertar de interesses por parte dos estudantes, além da motivação para a apropriação do conhecimento. Tanto o interesse quanto a motivação são características lúdicas que configuram as atividades de ensino e aprendizagem (Soares, 2013).

Tendo em vista o ensino de Ciências e sua relação com as TDIC, é importante ressaltar o papel do livro didático que também passa a considerar e evidenciar as tecnologias em suas propostas de ensino e aprendizagem, conforme discute Caiado (2011), ao analisar as relações entre as TDIC e o livro didático de Língua Portuguesa. Dessa forma, evidencia-se nos livros didáticos que passam pelo crivo do PNLD uma aproximação entre as TDIC e os estudantes em diferentes perspectivas. Outro ponto relevante a ser destacado é a relação entre a tecnologia e a criança considerando-se que os livros didáticos trazem em seu bojo referências tanto visuais como práticas de TDIC nas séries iniciais do Ensino Fundamental. Assim, o uso adequado da tecnologia é relevante para o processo de ensino e aprendizagem, pois as mídias se apresentam pedagogicamente sob três formas: através do conteúdo escolar, das competências e atitudes profissional, e como meio tecnológico de comunicação humana. E a partir dessas formas refletem efeitos didáticos como o desenvolvimento de pensamento autônomo, estratégias cognitivas, autonomia para organizar e dirigir seu próprio processo de aprendizagem, facilidade de análise e resolução de problemas, dentre outros aspectos (Libâneo, 2001).

Além do mais, as crianças que nasceram na chamada "era tecnológica", segundo Belloni e Gomes (2008), podem se apropriar com maior naturalidade desses novos aparatos tecnológicos por meio de experiências lúdicas e de aprendizagem. No entanto, mesmo entendendo o aspecto "naturalístico do uso das tecnologias" das crianças nascidas nessa era, é importante destacarmos alguns problemas que necessitam de atenção especial, como o abuso do uso das tecnologias que pode prejudicar o aprendizado e influenciar no comportamento da criança, pois, aqueles que não tinham ou tinham o uso controlado do computador se integravam mais facilmente com os colegas e os professores, além de ter maior presença e participação nas atividades de sala de aula. Em contraponto, aqueles que utilizavam largamente do computador, tinham facilidade para seu uso, no entanto, sua comunicação era limitada, seu círculo de amizade restrito e possuíam muita dificuldade em relação à concentração em abordagens escolares, à participação de atividades em grupo, e além do que, demonstravam repulsa a repreensões ou correções sobre questões nas quais cometiam erros conceituais (Batista Filho, 2011).

Corroborando com tais análises, Rowan (2014) sinaliza que é relevante se ter esse cuidado no uso de tecnologias pelas crianças com base em seu desenvolvimento. Tal apontamento da autora é baseado em um estudo da Academia Americana de Pediatria 
e a Sociedade Canadense de Pediatria, que afirma que a bebês de até 2 anos não se deve expor tecnologia e, às crianças que estão entre 3 e 5 anos, a restrição deve ser de 1 hora ao dia. $\mathrm{O}$ estudo complementa que para os que se encontram na faixa etária entre os 6 aos 18 anos, a exposição precisa de apenas 2 horas por dia, entretanto, o que se vê são quantitativos 4 ou 5 vezes maiores que o recomendado, e isso acarreta em consequências graves a esses indivíduos.

Tendo em vista a necessidade de um maior controle do uso da tecnologia pelas crianças que nasceram na era tecnológica, tema abordado por Rowan (2014), Belloni e Gomes (2008) e Batista Filho (2011), percebe-se que não se trata de uma questão que almeja a proibição, mas uma precaução visando cuidados com o desenvolvimento do indivíduo sob múltiplas facetas que perpassam a aprendizagem, como as relações sociais e o comportamento, dentre outras que podem refletir nos processos de interação entre sujeitos.

Acerca de pesquisas sobre a interação propiciada pelo livro didático nos apoiamos em Santos e Carneiro (2013), Pessoa (2009) e Ruas (2016). Sobre interação entre o livro didático e o leitor, Santos e Carneiro (2013) argumentam que o livro didático evoca funções destacando-se como guia do aluno no processo de apreensão do mundo exterior e, por meio dessa interação, o livro pode instigar o aluno ao desenvolvimento de seu próprio conhecimento ou mesmo para a repetição ou imitação do real. Os apontamentos de Santos e Carneiro (2013) também podem contribuir para compreendermos de que forma se constitui a instigação ao protagonismo do aluno por meio do desenvolvimento de seu próprio conhecimento ou repetição do real.

Posto isto, é relevante para o aluno que a informação e os estímulos se apresentem no livro didático a partir de meios diversos para desenvolvimento de seu aprendizado. Acerca do livro didático ter a função de guia, Pessoa (2009) evidencia, com relação ao seu estudo sobre as percepções sobre o livro didático, que os professores veem positivo o uso do livro principalmente para uso com os alunos em níveis iniciantes em determinado conteúdo exposto.

Nesse sentido, Ruas (2016) frisa aspectos que destacam formas de interação entre o estudante e o material didático, de forma geral considerando que "o estudante interage com o material didático, que pode ser composto em uma única mídia ou em multimídias, com textos, imagens (estática ou em movimento), áudio, realidade virtual, possibilitando assim a interação de diversas maneiras” (p. 90). Embora o autor aborde aspectos relacionados a material didático que pode ser acessado de forma remota, estabelecemos um paralelo ao visualizarmos as perspectivas de interação entre o leitor e o livro didático através de suas características dialógicas como: imagens, construção de trabalhos colaborativos com uso de internet ou não, dentre outros. 


\section{Procedimentos Metodológicos}

Esta pesquisa se configura no âmbito de uma pesquisa qualitativa. No entanto, para a coleta de dados foram utilizados instrumentos estatísticos cujos resultados subsidiaram as análises. Conforme Gatti (2002), quantidade e qualidade não se dissociam na pesquisa qualitativa, pois um significado precisa ser atribuído à grandeza numérica que expressa o fenômeno identificado. Na perspectiva qualitativa, realizamos uma análise documental e bibliográfica que, segundo Ludke e André (1996), consiste no levantamento de dados buscando identificar informações factuais nos documentos a partir de questões ou hipóteses de interesse da pesquisa.

Neste artigo são analisadas as coleções de Ciências dos anos iniciais do Ensino Fundamental aprovadas no GLD do PNLD 2019 com a finalidade de identificar as perspectivas de interação entre o leitor e LD a partir da temática das TDIC evidenciadas nos textos. No processo analítico organizou-se as interações identificadas em uma escala e fez-se uma tabulação quantitativa considerando-se as frequências com as quais as interações surgem nos textos.

Para o PNLD 2019 foram aprovadas 14 coleções de livros didáticos dos anos iniciais do Ensino Fundamental ( $1^{\circ}$ ao $5^{\circ}$ ano) no total de 70 livros didáticos de Ciências de acordo com a Portaria no 30 (MEC, 2018b) da Secretaria de Educação Básica, conforme apresentadas no Figura 1.

Figura 1. Coleções selecionadas no PNLD 2019 - Ciências

\begin{tabular}{|c|l|l|}
\hline Código Identificador & \multicolumn{1}{|c|}{ Editora } & \multicolumn{1}{c|}{ Coleção } \\
\hline C1 & Saraiva Educação S.A. & Ligamundo Ciências \\
\hline C2 & Editora Moderna Ltda. & Buriti Mais - Ciências \\
\hline C3 & Editora Moderna Ltda. & Novo Pitanguá - Ciências \\
\hline C4 & Editora do Brasil S.A. & Akpalô \\
\hline C5 & Editora FTD S.A. & Ciências \\
\hline C6 & Editora FTD S.A. & Conectados Ciências \\
\hline C7 & Editora Dimensão Ltda. & Coleção Quatro Cantos \\
\hline C8 & Leya Edições Educacional Ltda. & Odisséia \\
\hline C9 & Editora Ática & Ápis Ciências \\
\hline C10 & Edições SM Ltda. & Aprender Juntos Ciências \\
\hline C11 & Editora FTD S.A. & Encontros Ciências \\
\hline C12 & Edições Escala Educacional Ltda. & Anapiã \\
\hline C13 & Editora do Brasil S.A. & Crescer \\
\hline C14 & Edições SM Ltda. & Vamos Aprender Ciências \\
\hline
\end{tabular}

Fonte: Portaria no 30 (MEC, 2018b) da Secretaria de Educação Básica, adaptado.

Conforme Bogdan e Biklen (1994), o desenvolvimento de sistemas de codificação no processo investigativo se pauta em parâmetros semelhantes, enfocados 
em determinadas questões e preocupações de investigação dando origem às categorias de análise encontradas. O percurso analítico fundamentado em Bogdan e Biklen (1994), considerando a análise documental, se organizou em um processo de leitura dos documentos que são disponibilizados em formato Portable Document Format (PDF), buscando pelas referências a termos relacionados às TDIC, como palavras (link, smartphone, rede social, etc.) ou imagens. Após o destaque dados aos recortes selecionados, foi trabalhado o processo de construção das categorias considerando a codificação a partir de parâmetros de semelhança sem perder de vista as relações de interação proporcionadas. Em decorrência do volume de obras analisadas, o uso de ferramentas matemáticas para expressar a quantidade de elementos encontrados foi necessária para expressar estatisticamente os quantitativos relacionados aos elementos categorizados.

Então, a partir desses olhares às perspectivas de interação entre o leitor e livro didático, estabelecemos uma escala entre as categorias identificadas no sentido de observar as possibilidades de interação do leitor com o livro didático. A partir da observação e leitura dos LD foram construídas seis categorias acerca da temática das tecnologias digitais de informação e comunicação contidas nos livros didáticos de Ciências aprovados no edital do PNLD 2019. Essas categorias foram representadas pelas primeiras seis letras do alfabeto arábico, com fins de identificarmos e tipificarmos as perspectivas de interação entre o leitor e o livro didático nas obras em questão, elas são descritas na sequência:

A. Símbolos ou Grafias relacionados à temática: nesta categoria foram incluídos os símbolos utilizados nos livros que se assemelham aos utilizados na web, principalmente nas redes sociais. Também foram incluídos os termos linguísticos digitais ou aqueles que se adaptaram seu uso à internet como por exemplo, chat ou " $v c=v o c \hat{e}$ ".

Figura 2. Representação do uso de ícone análogo aos das redes sociais na Categoria $A$

\section{Como você vai fazer}

$\varepsilon^{2} 1$. Observem os itens que estão na lixeira da sala de aula ou no pátio da escola. Observem também a quantidade de cada item encontrado.

Fonte: C2 Livro do $5^{\circ}$ ano, p. 10.

B. Representação Visual relativa à temática: nesta categoria foram incluídas as imagens ou textos isolados em que apenas o aparato tecnológico é representado, sem nenhuma interação ou conexão com atividade proposta ou mesmo seu uso por meio de representação. 
Figura 3. Representação do uso de tablet na Categoria $B$

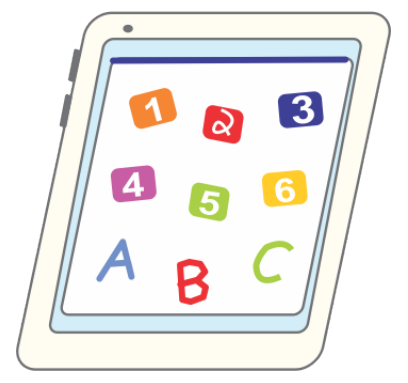

Fonte: C5 Livro do $3^{\circ}$ ano, p. 144.

C. Representação de Uso Prático relativo à temática: nesta categoria foram incluídas as imagens ou textos em que se mostra ou se representa a utilização de TDIC no LD.

Figura 4. Representação do uso de smartphone na Categoria $C$

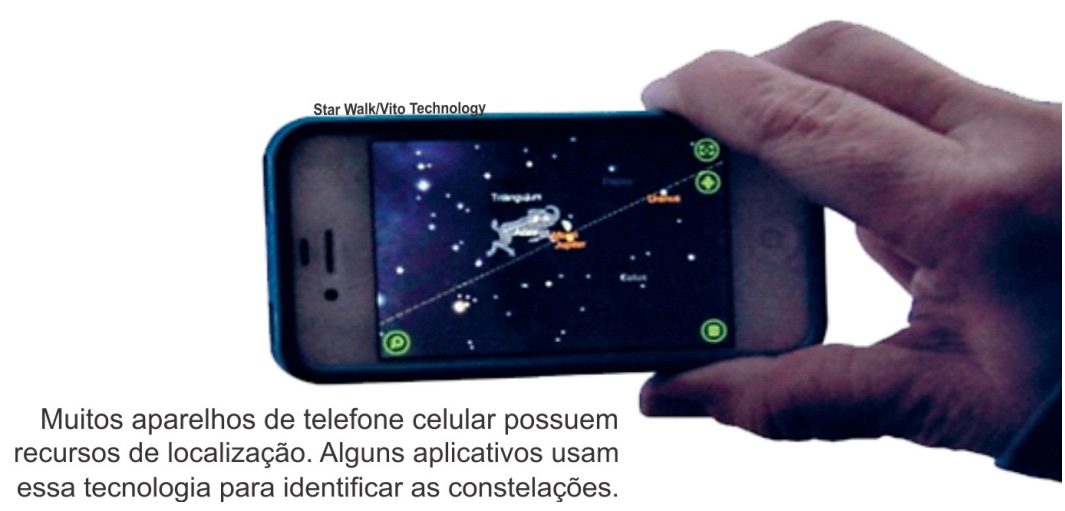

Fonte: C1 Livro do 5º ano, p. 177.

D. Texto relativo à temática: nessa categoria foram incluídas as abordagens que tratam sobre textos ou fragmentos de textos, especificamente de TDIC, como computador, internet, dispositivos móveis, dentre outros.

Figura 5. Representação de texto sobre selfie na Categoria $D$

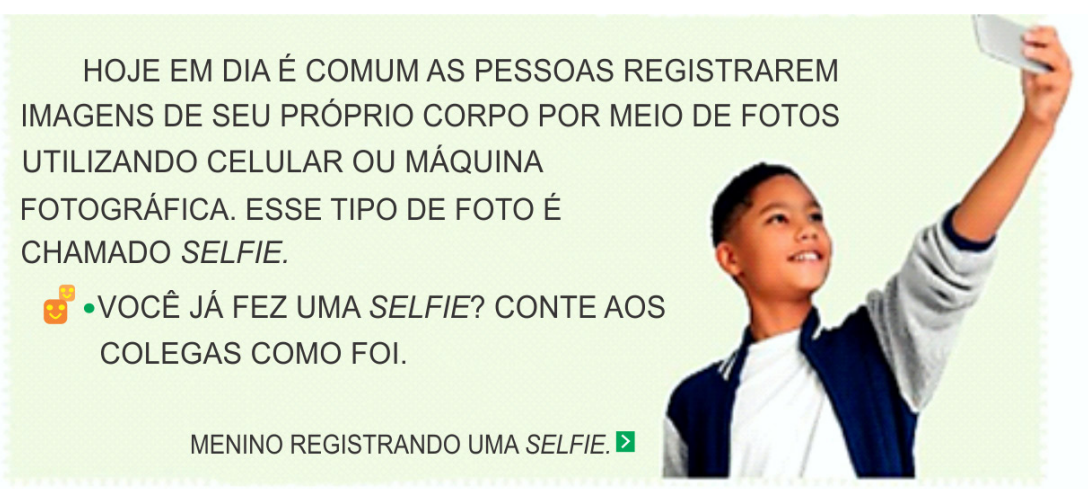

Fonte. C3 Livro do $1^{\circ}$ ano, p. 11. 
E. Referências Externas relativas à temática: nesta categoria foram incluídos os textos ou fragmentos de textos retirados de sites, como também os links disponíveis para acesso a determinados páginas web, a fim de aprofundamento do conhecimento.

Figura 6. Representação de uso de links na Categoria $E$

Leia as notícias a seguir.

Primeira escola de garrafas PET é construída na Ásia

Construída em San Pablo, nas Filipinas, a escola feita com garrafas plásticas descartadas é a primeira deste tipo na Ásia. [...] O objetivo do projeto é conscientizar a população sobre a importância da construção de novas escolas, além de dar novo uso a um material com descarte considerado problemático nos dias de hoje. [...]

Ciclo Vivo. Disponivel em: <http://ciclovivo.com.br/noticia/ primeira_escola_de_garrafas_pet_e_construída na_asia>. Acesso em: 30 nov. 2017.

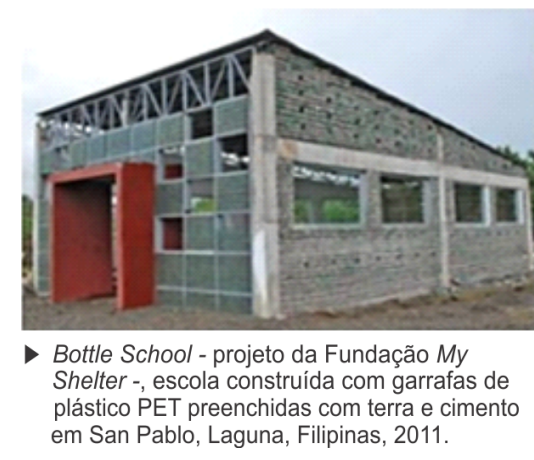

Fonte: C4 Livro do $5^{\circ}$ ano, p. 47.

F. Propostas de Atividades relativas à temática: nesta categoria foram incluídas as atividades que são propostas aos alunos com o uso de TDIC para a sua realização.

Figura 7. Representação uso de atividades práticas na Categoria $F$

1. Usando uma das formas de identificação dos astros celestes menciona-

目 das nestas páginas, localize e identifique algumas constelações visíveis na região onde você mora. Depois, pesquise em livros e na internet os periodos do ano em que as constelações observadas por você são visíveis no início da noite.

Fonte: C6 Livro do 5ªno, p. 161.

Além da criação das categorias citadas, apresentamos as frequências quantitativas conforme os elementos relacionados às TDIC identificados nas coleções. Acerca das frequências, estas configuram-se como o número de vezes em que algum elemento relacionado a TDIC aparece no livro didático do componente curricular de ciências. No entanto, é relevante realçar que a análise documental das obras considerou que, nos procedimentos dos cálculos das frequências, a estimativa de erro relativo percentual quando for o caso - não é maior que $0,01 \%$. Esse erro relativo percentual é a diferença entre o valor que se obteve e o percentual máximo que é 100, que neste caso, se deu por conta dos cálculos provenientes dos arredondamentos dos números. Então, a partir dessas frequências se construíram tabelas quantitativas para a melhor visualização do objeto analisado neste estudo, e por conseguinte, uma discussão sobre os dados apresentados.

Posto isto, a temática da TDIC é utilizada para suas inserções no livro didático possibilitando a construção das categorias para analisarmos as perspectivas de interação existentes entre o leitor e o livro didático, sendo este o objeto de análise deste estudo em questão. 


\section{Resultados e Discussões}

Apresentamos a seguir, a distribuição das frequências sobre as inserções de TDIC nos LD tabuladas quantitativamente, através da análise de suas respectivas categorias nas catorze coleções de livros didáticos de Ciências do $1^{\mathrm{a}}$ a $5^{\mathrm{a}}$ ano e seus setenta livros - aprovadas no PNLD 2019. Dessa forma, passamos às análises comparativas entre as categorias, constante na Tabela 1.

Tabela 1. Frequências Consolidadas das Coleções - por Categoria

\begin{tabular}{ccccccc}
\hline & A & B & C & D & E & F \\
\hline C1 & 41 & 16 & 9 & 1 & 84 & 49 \\
C2 & 2 & 21 & 12 & 2 & 19 & 13 \\
C3 & 10 & 17 & 8 & 3 & 31 & 16 \\
C4 & 8 & 13 & 13 & 5 & 137 & 17 \\
C5 & 0 & 35 & 10 & 3 & 66 & 28 \\
C6 & 3 & 24 & 7 & 6 & 80 & 27 \\
C7 & 0 & 13 & 2 & 0 & 161 & 13 \\
C8 & 8 & 21 & 13 & 0 & 30 & 14 \\
C9 & 2 & 33 & 11 & 0 & 19 & 1 \\
C10 & 34 & 59 & 6 & 2 & 96 & 23 \\
C11 & 8 & 5 & 10 & 4 & 132 & 24 \\
C12 & 5 & 9 & 5 & 1 & 53 & 4 \\
C13 & 1 & 3 & 7 & 1 & 72 & 26 \\
C14 & 0 & 8 & 4 & 0 & 64 & 9 \\
\hline Valor percentual (por categoria) & $6,59 \%$ & $14,96 \%$ & $6,32 \%$ & $1,51 \%$ & $56,37 \%$ & $14,25 \%$ \\
\hline
\end{tabular}

Fonte: Autoria própria.

Partimos para a análise quantitativa da inserção dos elementos de TDIC que estão dispostos no "Valor percentual (por categoria)". Dessa forma, organizamos quatro tipos de divisões a partir do quantitativo total de frequências presentes nos livros didáticos:

- Valores $\geq 15 \%$ - Categoria E (56,37\%);

- Valores $\geq 10 \%$ e $<15 \%$ - Categorias B $(14,96 \%)$ e Categoria F $(14,25 \%)$;

- Valores $\geq 5 \%$ e $<10 \%$ - Categorias A (6,59\%) e Categoria C (6,32\%);

- e por fim, Valores $\geq 0 \%$ e $<5 \%$ - Categoria $\mathrm{D}(1,51 \%)$.

A primeira divisão se dá pelo predomínio da categoria E. Essa categoria assume a primeira posição por estarem contidos nela, primordialmente, links disponíveis para acesso a determinadas páginas web que objetivam o aprofundamento de algum tema abordado no LD. Os links mostram-se como ferramentas recentes nos livros que estabelecem um diálogo com outras esferas de conhecimentos como revistas científicas, sítios de conteúdos escolares, projetos de ciência, etc. Ao observarmos que estes links 
estão dispostos por todas as coleções em quantidades expressivas frente às demais categorias, inferimos com isso que uma das razões para tal resultado de predomínio da categoria E, é que esta é uma forma de associar o uso da internet ao LD. Nessa perspectiva, os LD atendem ao edital que está vinculado à Base Nacional Comum Curricular (MEC, 2018a) que sinaliza as relações dos estudantes com as tecnologias, além de estimular seu protagonismo ao ampliar a compreensão de si e do mundo que o cerca. Essa tendência ao uso de links é reforçada por Coscarelli e Martins (2009) quando discorrem sobre a presença dessas referências do ambiente digital no livro didático impresso, destacando sua pertinência a prática docente ao facilitar o acesso a determinados conteúdo específicos, muito embora as formas de se explorar tais referências sejam, por vezes, difíceis de se encontrar ou mesmo inexistentes.

A segunda divisão refere-se às categorias B e F que, embora tenham frequências próximas, são díspares em suas características. A categoria B é uma perspectiva mais visual pois é representada por meio das imagens relativas a TDIC, temática dessa pesquisa. No que se refere à importância das imagens nos processos de ensino e aprendizagem no campo do ensino de ciências, Martins et al. (2005) discorrem que as imagens são importantes recursos para a comunicação de ideias científicas e nas conceituações por contribuírem para a inteligibilidade de diversos textos. Além disso, a questão do uso de imagem é objeto de um crescente conjunto de investigações que objetivam, dentre outros aspectos, o compartilhamento do "interesse de melhor compreender as relações entre as imagens, conhecimento científico e ensino de ciências" (idem, p. 38). No que tange a categoria $\mathrm{F}$, esta vislumbra uma instigação à prática a partir de orientações propostas no LD e, com isso, estimula a colaboração em desenvolvimento de pesquisas mais simples ou mais complexas por parte dos alunos, com outros alunos ou mesmo com os professores. No ensino de ciências também não é diferente a importância de instigação à prática para os alunos por meio das atividades de campo nas quais as salas de aula são substituídas pelo ambiente natural, ou não, para se estudar os seres vivos e suas relações, além das próprias interações do homem nesse espaço. Essa prática pode se dar nas praças, jardins, museus, indústrias, áreas de preservação, saídas no entorno da escola ou até viagens que durariam vários dias, e dessa forma, essas atividades podem se constituir em alternativas metodológicas que possibilitam explorar as formas de abordagem dos conteúdos, sempre de maneira planejada (Viveiro \& Diniz, 2009). Essas relações se coadunam às observações anteriores que evidenciam os direcionamentos educacionais em termos de ampliação dos saberes, por diversos meios tanto interno ao ambiente escolar como externo a ele.

Nota-se que são categorias que partem da visualização das imagens e de textos relativos à temática de TDIC, mas não fazem menção a páginas ou links de internet. Muito embora saibamos que os livros são repletos de ilustrações, ao pesquisarmos por elementos característicos das TDIC, tal proporção se dilui em meio a tantos temas abordados no livro didático. Em relação à categoria $\mathrm{A}$, que trata sobre símbolos ou grafias concernentes às TDIC, Liz e Quarezemin (2014) explicitam que a utilização das formas 
de escrita da internet pode ser uma estratégia para incentivar o processo de escrita pelos estudantes, pois difunde a língua materna e, dessa forma, os autores se contrapóem à ideia de que uso de redes sociais “está contaminando a língua ou a pureza dela" (p. 174). No que se refere a categoria $\mathrm{C}$, que traz representações de utilização prática das TDIC, podemos destacar a argumentação de Carvalho (2016), ao evidenciar a importância de se utilizar todo o potencial advindo da imagem para o ensino aprendizagem, pois os elementos visuais não apenas se configuram como adições ao texto verbal, mas também se caracterizam como elementos importantes na construção de significados. Nesse viés, a autora salienta que podem ocorrer usos inadequados de imagens em sala de aula que, nessa perspectiva não contribuiriam no processo de ensino e aprendizagem. Dessa forma, a escolha de imagens para compor um texto de livro didático e seu uso em sala de aula podem contribuir ou atravancar as abordagens de ensino as quais estão sendo propostas para o aprendizado do aluno.

A quarta e última divisão é referente à categoria D. Essa categoria trata das abordagens sobre textos ou fragmentos de textos relativos à temática da TDIC. Entendemos que esta categoria tem relação com as diretrizes da educação nacional que considera a necessidade de que os materiais didáticos se apropriem de "fontes reconhecidas e atualizadas e que ampliem conceitos e informações" (MEC, 2017). Em nosso foco analítico, tratamos sobre as TDIC que se constituem como tema de relevância nos dias de hoje para o ensino de ciências, como é disposto por Silva e Barbosa (2016) ao afirmarem que o uso das tecnologias digitais desempenham um papel relevante e positivo para o ensino de ciências, tendo em vista que estes são recursos que promovem interesse e envolvimento com o conteúdo apresentado, principalmente entre os jovens.

Em suma, temos na Tabela 1 a representação das frequências nos livros didáticos considerando as coleções e categorias. Ao analisarmos os dados, inferimos que as categorias que tendem à prática $(\mathrm{E}$ e $\mathrm{F})$ são mais representativas em relação as mais visuais (A, B, C e D), e também que todas as coleções possuem elementos presentes nas categorias em maior ou menor grau. Não pode-se afirmar que categorias práticas são mais ou menos eficazes que categorias visuais em termos de ensino e aprendizagem, pois cada indivíduo possui o seu próprio modo de aprender que perpassa por vários estilos de aprendizagem e, para Schmitt e Domingues (2016), "o uso dos modelos de estilos de aprendizagem deve permitir que os alunos e professores possam estudar e procurar com mais cuidado os fatores e atividades que proporcionem a eficiência da aprendizagem" (p. 380). A partir disso, entendemos que os LD, ao trazerem elementos variados relacionados às TDIC, ampliam as possibilidades de atendimento a diferentes estilos de abordagem dos conhecimentos científicos pelos alunos em sala de aula.

Podemos concluir, dessa forma, a importância dessas categorias no contexto escolar, especificamente na área de Ciências da Natureza, na qual as relações entre os conhecimentos científicos e as tecnologias mostram-se pertinentes na construção de um projeto de educação que visa a formação de pessoas alfabetizadas cientificamente. Acerca da alfabetização científica Marcondes (2018) argumenta de que há um consenso hoje 
em dia da necessidade do conhecimento científico a todos, pois esses conhecimentos contribuem, de forma substancial, tanto na vida pessoal quanto profissional dos indivíduos trazendo reflexões sobre questões sociais que os rodeiam. A vista disso, as categorias podem sinalizar caminhos para a alfabetização científica do leitor que, de alguma forma, encontra-se imerso em um mundo permeado por diferentes tecnologias que podem ser abordadas pela escola e pelos instrumentos do processo de ensino e aprendizagem. Sendo o livro didático um destes instrumentos da escola, a inserção das tecnologias pode se configurar como elemento de alfabetização científica, pois conforme Chassot (2003, p. 91) "ser alfabetizado cientificamente é saber ler a linguagem em que está escrita a natureza. É um analfabeto científico aquele incapaz de uma leitura do universo".

Após realizarmos a análise quantitativa percentual das categorias, passamos à Tabela 2 na qual trazemos a análise em relação a seriação/ano escolar. Dessa forma, passamos às análises comparativas considerando-se a seriação ou ano escolar.

Tabela 2. Frequência Consolidada das Coleções - Por Seriação ou Ano Escolar

\begin{tabular}{cccccc}
\hline & $\mathbf{1}^{\mathbf{0}}$ Ano & $\mathbf{2}^{\mathbf{o}}$ Ano & $\mathbf{3}^{\mathbf{0}}$ Ano & $\mathbf{4}^{\mathbf{o}}$ Ano & $\mathbf{5}^{\mathbf{0}}$ Ano \\
\hline C1 & 10 & 38 & 47 & 46 & 59 \\
\hline C2 & 11 & 9 & 18 & 14 & 17 \\
\hline C4 & 13 & 9 & 10 & 22 & 31 \\
\hline C5 & 26 & 29 & 34 & 42 & 62 \\
\hline C6 & 14 & 18 & 24 & 40 & 46 \\
\hline C7 & 16 & 34 & 30 & 33 & 34 \\
\hline C8 & 23 & 33 & 28 & 40 & 65 \\
\hline C9 & 12 & 3 & 11 & 41 & 19 \\
\hline C10 & 9 & 10 & 6 & 9 & 32 \\
\hline C11 & 25 & 46 & 56 & 35 & 58 \\
\hline C12 & 21 & 28 & 31 & 46 & 57 \\
\hline C13 & 13 & 5 & 13 & 14 & 32 \\
\hline C14 & 8 & 18 & 27 & 28 & 29 \\
\hline Valor total (por seriação) & 205 & 294 & 355 & 432 & 566 \\
\hline Valor percentual (por seriação) & $11,07 \%$ & $15,87 \%$ & $19,17 \%$ & $23,33 \%$ & $30,56 \%$ \\
\hline
\end{tabular}

Fonte: Autoria própria.

Em relação às frequências por seriação da totalidade das coleções, se percebe uma oscilação nas frequências a partir do $1^{\circ}$ ano, de forma progressiva. Dessa forma, tal direcionamento corrobora com as perspectivas de Rowan (2014) e Batista Filho (2011) que propõem o uso prudente das tecnologias com crianças. Nesse sentido, Rowan (2014, p. 1) afirma que "as crianças são o nosso futuro, mas não há futuro para as crianças com overdose de tecnologia". Batista Filho (2011, p. 1) argumenta que "só temos que 
ficar atentos com as crianças, e a influência disso em sua educação, senão teremos uma sociedade formada por milhões de pessoas interligadas pela internet, mas separadas pela tecnologia”. Entendemos então que a interação entre os alunos e as TDIC por meio do livro didático é vista de forma cautelosa em seu uso nos primeiros anos do Ensino Fundamental tendo em vista o crescimento, amadurecimento e responsabilidade das crianças no uso dos aparatos tecnológicos. Outrossim, nas séries que atendem alunos de maior idade, é maior a frequência das TDIC, pois leva-se em conta que a criança está mais familiarizada com tais aparatos.

Após analisarmos os dados das frequências no que tange às seriações relacionadas às categorias já dispostas na pesquisa, nos debruçaremos a identificar as perspectivas de interação entre o livro didático e o leitor a partir dessas categorias. Propomos uma esquematização das perspectivas de interação entre o leitor e o livro didático. Esse esquema foi construído a partir da observação das categorias levantadas nesta pesquisa estabelecendo, com isso, formas de uso do livro didático, conforme Figura 8.

Figura 8. Perspectiva de Interação com o Livro Didático de Ciências dos Anos Iniciais

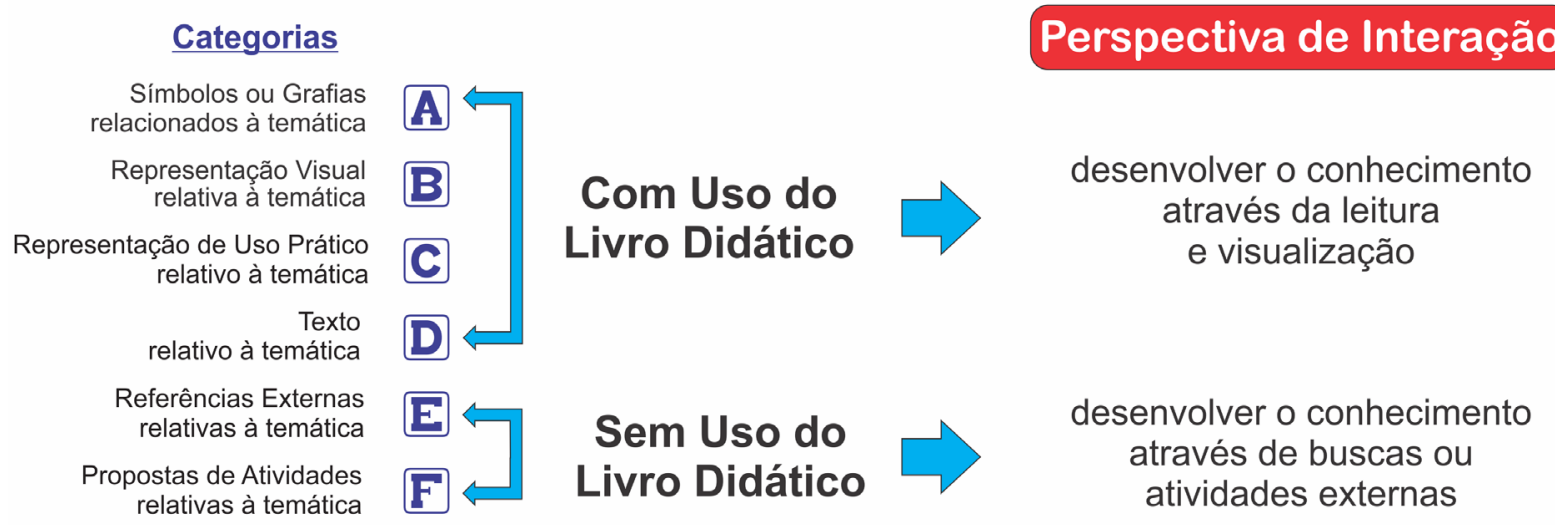

Fonte: Próprio autor.

Nessa esquematização podemos dividir em três partes que estão encadeadas por sequência, a saber:

- As categorias construídas;

- O uso ou não uso do livro didático;

- As perspectivas de interação identificadas entre o leitor e livro didático.

A primeira parte fala da própria categorização construída. Essa categorização foi elaborada a partir da leitura e observação dos livros didáticos, ou seja, ela não estava pronta a priori, mas foi construída em movimentos de análise dos documentos. Por meio das categorias identificadas, podemos notar que as categorias A, B e C são baseadas em elementos visuais, tendo em vista serem identificadas por meio dos símbolos e grafias, além do uso de imagens para apresentar a informação ao aluno. De outro ponto, a categoria $\mathrm{D}$ é identificada a partir da disposição de textos relativos às tecnologias, assim, a informação é prestada ao aluno a partir dessa descrição da temática. Além dessas 
categorias temos a categoria $\mathrm{E}$, na qual percebe-se a internet como a grande provedora dessa fonte, muito embora, também possamos encontrar outras tecnologias também presentes como o cinema e o livro, mas, em menor grau nas pesquisas realizadas nos livros didáticos. E por fim, a categoria $\mathrm{F}$ que instiga a partir de referências propostas em atividades ou experiências práticas presentes nos livros didáticos, as realizações de atividades colaborativas ou individuais externas a ele, com a finalidade de trazer o "aprender fazendo" por meio da prática ao qual o aluno estaria construindo também o seu próprio aprendizado orientado ou não, sozinho ou colaborativamente.

A segunda parte do esquema refere-se à divisão na qual visualizarmos as categorias que usam diretamente do livro didático, como as que não utilizam do livro didático, pois este se dá como referência a atividades que devem ser realizadas externamente a ele, mas, sob sua orientação. E assim, podemos dizer que as categorias de A até D, utilizariam diretamente o livro didático, e de outro lado, as categorias E e F, abordariam atividades mais práticas em que o livro seria um norteador a realização dessas atividades externamente.

$\mathrm{Na}$ terceira parte do esquema, podemos concluir e indicar as perspectivas de interação identificadas nos livros didáticos de ciências dos anos iniciais do Ensino Fundamental, referentes ao PNLD 2019. Então, a partir da construção das categorias e suas características próprias, identificamos duas perspectivas de interação entre o leitor e o livro didático com fins ao desenvolvimento do conhecimento pelo aluno, estas são:

- Desenvolver o conhecimento através da leitura, escrita e visualização;

- Desenvolver o conhecimento através de buscas ou atividades externas.

No primeiro caso, estão atreladas as categorias de A até $\mathrm{D}$, a partir do próprio uso do livro didático através das imagens, símbolos, textos, além logicamente dos exercícios e atividades propostas e respondidas nos mesmos. Ou seja, o uso do próprio livro para gerar o conhecimento consiste em uma forma de uma interação, por meio da leitura, escrita e visualização das imagens. No entanto, podemos destacar que muito embora haja a interação direta entre o leitor e o livro didático, o papel do mediador/professor, segundo Bittencourt (2005), é imprescindível a partir da necessidade de formação de uma postura crítica pelo leitor. Para o referido autor, os livros são considerados pouco motivadores em comparação às imagens midiáticas às quais os estudantes têm acesso. Vislumbramos, nesse viés, a importância de livros didáticos que, por meio da inserção de novos elementos relacionados às TDIC, possam, com a mediação do professor, se tornar mais interativos, despertando interesses de busca de informações para além do texto escrito.

No segundo caso, estão atreladas as categorias E e F a partir da instigação da busca em referências externas, como em sites, livros, filmes, dentre outros, como também a realização de atividades práticas externas, sejam elas colaborativas ou individuais como construção de blogs, realização de experiências básicas de ciências, dentre outras. Ou seja, o livro como ferramenta de orientação norteadora à busca em fontes externas se configura como outra forma de interação. No entanto, mesmo em tais referências externas 
nas quais a prática é realçada, é preciso haver relações com questões problematizadoras e não apenas verdades estabelecidas e inquestionáveis para simples reproduções com a finalidade de instigar a crítica pelo leitor. Essa argumentação encontra respaldo em Wesendonk, Rodrigues e Terrazzan (2011) quando em seu estudo sobre Atividades Didáticas Experimentais - ADE em livros didáticos relativos ao ensino de física e ensino de biologia, concluem que praticamente não há $\mathrm{ADE}$ nos livros que desafiem o aluno a buscar resoluções de caráter experimental, pois estão propostas basicamente de modo a verificar aspectos conceituais já estabelecidos no campo da Ciência. Em contraponto a isso, os autores salientam que as ADE devem incorporar "questões problematizadoras, espaço para a discussão de todo o procedimento experimental e interpretação dos resultados experimentais" (p. 12).

Ao entrelaçarmos nossos resultados aos referenciais que nos auxiliaram na fundamentação teórica, destacamos Santos e Carneiro (2013) e Pessoa (2009), que ressaltam o LD como guia do aluno na apreensão do mundo exterior e evidenciam, a partir dessa perspectiva, as possibilidades de desenvolvimento do conhecimento a partir também da imitação do real, além da importância do uso com os alunos em nível iniciante. Em nossas análises, identificamos o alinhamento ao abordado pelos autores com base na segunda perspectiva de interação que trata do "Desenvolver o conhecimento através de buscas ou atividades externas", considerando-se que essa perspectiva de interação remete à Categoria E "Referências Externas relativas à temática" e à Categoria F "Propostas de Atividades relativas à temática”. As duas categorias tratam da realização, pelos alunos, de atividades que estimulam a apreensão do mundo que os rodeia, podendo ser por meio de atividades práticas ou experimentais que, de certo modo, instigam a busca do conhecimento em outras fontes, podendo ser estas físicas ou virtuais. Essa abertura a um universo fora do LD amplia perspectivas de acesso ao conhecimento científico e, com isso, pode contribuir com o processo de alfabetização científica pontuado por Marcondes (2018) e Chassot (2003).

A análise realizada também corrobora a perspectiva de Ruas (2016) sobre a interação de estudantes com o livro ser possibilitada a partir da inserção de elementos relacionados às TDIC, tais como links que levam o estudante a artigos e textos de caráter científico e reforçam atividades a serem realizadas para além do LD. Para o referido autor, as características dialógicas como imagens, textos, áudios, realidade virtual/aumentada, elementos da web, e outras fontes diversas, relacionam-se com o aluno e se constituem como influenciadoras diretas no processo de interação referente ao texto didático. Os textos e imagens nos remetem às Categorias, $\mathrm{B}, \mathrm{C}$ e $\mathrm{D}$ que perfazem quase a totalidade a primeira perspectiva de interação que trata de "Desenvolver o conhecimento através da leitura, escrita e visualização". Em referência aos áudios, realidade virtual/aumentada e elementos web, nos reportamos à segunda perspectiva de interação que trata do "Desenvolver o conhecimento através de buscas ou atividades externas". Dessa forma, identificamos, por meio da análise dos livros de Ciências referentes às séries iniciais do Ensino Fundamental, elementos que sinalizam interações entre os estudantes e os livros considerando as abordagens das TDIC nos textos em tela. 


\section{Conclusões e Implicações}

No sentido de trazer ao leitor as considerações finais para a pesquisa realizada, retomamos o objetivo da investigação que se propôs a analisar os livros de Ciências, dos anos iniciais do Ensino Fundamental, aprovados no PNLD de 2019 visando identificar as perspectivas de interação presentes entre o leitor e o livro didático tendo em vista elementos relacionados às TIDIC presentes nos LD. Por meio da análise realizada, identificamos duas perspectivas de interação entre o leitor e o livro didático, sendo que a primeira trata do uso do LD considerando a leitura, escrita e visualização e a segunda instiga o estudante a buscas ou atividades externas sinalizadas pelo próprio livro. A identificação dessas duas perspectivas de interação foi possível por meio da construção e discussão de seis categorias. Essas categorias foram levantadas por meio da observação e quantificação das diferentes formas de abordagens relacionadas às TDIC que foram dispostas no livro didático.

As discussões realizadas a partir dos resultados explicitados no contexto desta pesquisa trazem destaque ao processo de interação mobilizado pelas tecnologias por meio dos livros didáticos de Ciências aprovados no PNLD 2019. Entendemos que tal discussão é importante dada a relevância às tecnologias que é impressa ao edital de 2019 e que, provavelmente, será aprofundada em editais próximos considerando-se que, no referido documento, há ênfase nas experiências das crianças bem como nas interações entre estas e as diversas tecnologias da informação e comunicação como fontes de estímulo à curiosidade infantil. Isso posto, torna-se importante que tais aspectos se configurem como universo investigativo no âmbito da pesquisa na área de Ensino de Ciências. Outrossim, este resultado dialoga com a literatura que nos apresenta o uso de TDIC como parte presente na vida das crianças e jovens que são leitores e, ao mesmo tempo, alunos do ensino fundamental, desse modo corroborando a perspectiva de que o livro didático não está anacronicamente alheio às inovações tecnológicas dos dias atuais, e sim se apropriou de elementos como a internet inserindo esta temática por meio de links relacionados a sites da web.

Ademais, como observações complementares advindas desse estudo destacamos dois pontos. O primeiro ponto dialoga com o fato de que, a partir da identificação de elementos que caracterizam a inserção das TDIC nos textos, observamos que nas primeiras séries há menor exposição dos estudantes a aspectos referentes às tecnologias e que há diferentes formas de inserção das TDIC no LD. O segundo ponto destaca que, independentemente da perspectiva de interação, é necessário que esta seja pensada desde sua concepção em um sentido que instigue a reflexão, a criatividade e a criticidade do leitor, e não apenas se baseie na reprodução de verdades estabelecidas e inquestionáveis, principalmente no que se refere às práticas externas ao livro.

Dessa forma, entendemos que nossos resultados corroboram autores que salientam a importância de diminuir a exposição de crianças menores ao uso de tecnologias, pois os LD analisados sinalizam que, quanto mais inicial a série, menos relações se efetivam em termos de interação entre o leitor e o LD por meio de tecnologias. Essa análise 
pode contribuir para trazer à luz diferentes olhares sobre as propostas de inserção das tecnologias em diversos níveis de ensino que, sem uma reflexão atenta sobre o tema, podem desconsiderar cuidados necessários e protetivos para os estudantes que ainda não conseguem lidar de forma autônoma com estas ferramentas. Ao nos referirmos a "outros olhares" nos remetemos à possibilidade que também sejam investigadas as interações de LD de outras áreas como Linguagens e Matemática no que diz respeito à inserção das tecnologias nestes textos em um movimento de interação com os leitores.

Entendemos que as relações impressas entre o LD e o leitor, a partir de vieses das tecnologias, tem sido estimuladas por meio de editais do Programa Nacional do Livro Didático e que um estudo aprofundado se faz necessário, pois o acesso às tecnologias por estudantes brasileiros de escolas públicas ainda é sombreado por elementos que caracterizam a exclusão social e que, ao se inserir de forma mais contundente as tecnologias no contexto da sala de aula, sendo difundidas pelos LD, é possível reforçar o papel da escola como mantenedora de privilégios e reprodutora de desigualdades sociais. Salientamos que as ferramentas estatísticas que balizaram o movimento analítico e que evidenciaram as referências às tecnologias, bem como as categorias que emergiram nesse processo, possibilitam novos estudos considerando-se que a socialização desta pesquisa, e de seus elementos metodológicos, insere-se no modus operandi do ato de pesquisar no qual há a socialização dos resultados e dos caminhos metodológicos da pesquisa no sentido de que esta possa ser replicada, e ou adequada, em diferentes contextos. $\mathrm{O}$ foco da pesquisa relaciona-se ao LD das fases iniciais de Ciências do Ensino Fundamental, mas ainda há lacunas que podem ser deslindadas no que concerne também aos LD de Química, Física e Biologia do Ensino Médio, cujos editais também assinalam a inserção das tecnologias nos textos dos livros a serem distribuídos às escolas públicas.

Importante destacarmos que, embora tenhamos, de certa forma, alcançado os objetivos propostos para esse recorte investigativo, há dimensões do processo de ensino e aprendizagem para além das perspectivas aqui discutidas, pois existe todo um cenário educacional que envolve desde a formação dos professores, passando pela estrutura física da escola e acesso dos alunos a outros espaços tecnológicos. Este é apenas um início de conversa.

\section{Referências}

Baganha, D. E., \& Garcia, N. M. (2011). O papel e o uso do livro didático de Ciências nos anos finais do Ensino Fundamental. In VIII Encontro Nacional de Pesquisa em Educação em Ciências - ENPEC, (pp. 1-12). Campinas, SP. http://www.nutes.ufrj.br/abrapec/ viiienpec/resumos/R1526-1.pdf

Belloni, M. L., \& Gomes, N. G. (2008). Infância, mídias e aprendizagem: Autodidaxia e colaboração. Educação \& Sociedade, 29(104), 717-746. https://doi.org/10.1590/S010173302008000300005 
Bittencourt, C. (2005). Livros Didáticos entre Textos e Imagens. In C. Bittencourt (Org.), O Saber Histórico na sala de Aula (pp. 69-90). Editora Contexto. https://edisciplinas.usp. br/pluginfile.php/4246858/mod_resource/content/1/Livros\%20did\%C3\%A1ticos\%20 entre\%20textos\%20e\%20imagens

Bogdan, R., \& Biklen, S. K. (1994). Investigação qualitativa em educação: Uma introdução à teoria e aos métodos. Porto Editora.

Brasil (2020). Catálogo de Teses e Dissertações da Capes. https://catalogodeteses.capes. gov.br/catalogo-teses/\#!/

Caiado, R. V. (2011). Novas tecnologias digitais de informação e comunicação e o ensino e aprendizagem de Língua Portuguesa. (Tese de Doutorado em Educação). Centro de Educação, Universidade Federal de Pernambuco, Recife-PE. https://repositorio.ufpe.br/ handle/123456789/3900

Carvalho, S. A. (2016). As interações imagem-texto em material didático online para a formação a distância de professores de inglês. (Tese de Doutorado em Linguística Aplicada). Centro de Humanidades, Universidade Estadual do Ceará, Fortaleza-CE. http://www.uece.br/posla/wp-content/uploads/sites/53/2020/01/TESE_S\%C3\%82MIAALVES-CARVALHO.pdf

Chassot, A. I. (2003). Alfabetização científica: Uma possibilidade para a inclusão social. Revista Brasileira de Educação, (22), 89-100. https://doi.org/10.1590/S141324782003000100009

Coscarelli, C. V., \& Martins, E. (2009). O livro didático como agente de letramento digital. In Costa Val, M. da G. (Org.), Alfabetização e língua portuguesa: Livros didáticos e práticas pedagógicas (pp. 171-188). Autêntica Editora, Ceale/FaE.

Costa, S. R. S., Duqueviz, B. C., \& Pedroza, R. L. S. (2015). Tecnologias Digitais como instrumentos mediadores da aprendizagem dos nativos digitais. Psicologia Escolar $e$ Educacional, 19(3), 603-610. https://doi.org/10.1590/2175-3539/2015/0193912

Batista Filho, O. H. (2011). A infância e a computação. http://www.hardware.com.br/ artigos/infancia-computacao

Fellini, R. (2012). Livro Didático, Interação e Ensino. Fragmentum, 35(2), 42-49. https:// periodicos.ufsm.br/fragmentum/article/viewFile/7873/4743

Garcia, Nilson Marcos Dias. (2012). Livro didático de Física e de Ciências: Contribuições das pesquisas para a transformação do ensino. Educar em Revista, (44), 145-163. https:// doi.org/10.1590/S0104-40602012000200010

Gatti, B. A. (2002). A construção da pesquisa em educação no Brasil. Plano Editora.

Kenski, V. M. (2003). Tecnologias e Ensino Presencial e à Distância: Práticas Pedagógicas. Papirus. 
Leite, A. E., Garcia, N. M. D., \& Rocha, M. (2011). Tendências de Pesquisa Sobre os Livros Didáticos de Ciências e Física. In X Congresso Nacional de Educação - EDUCERE, (pp. 11739-51). Curitiba, PR. https://educere.bruc.com.br/arquivo/pdf2011/6243_3800.pdf

Libâneo, J. C. (2001). Adeus professor, adeus professora. Cortez.

Liz, L. L. de, \& Quarezemin, S. (2014). Formação de professores dos anos iniciais da Educação Básica na modalidade EaD: Ensino de língua materna e a influência das Tecnologias da Informação e Comunicação. Educar em Revista, (spe 4), 173-190. https:// doi.org/10.1590/0104-4060.38659

Lüdke, M., \& André, M. E. (1996). Pesquisa em educação: Abordagens qualitativas. EPU. Marcondes, M. E. R. (2018). As Ciências da Natureza nas $1^{\text {a }}$ e $2^{\text {a }}$ versões da Base Nacional Comum Curricular. Estudos Avançados, 32(94), 269-284. https://doi.org/10.1590/ s0103-40142018.3294.0018

Martins, I. Gouvêa, G., \& Piccinini, C. (2005). Aprendendocom imagens. Ciênciae Cultura, 57(4), 38-40. http://cienciaecultura.bvs.br/scielo.php?script=sci_arttext\&pid=S0009$67252005000400021 \& \operatorname{lng}=$ en \&tlng $=$ pt.

MEC (2008). Guia de Tecnologias Educacionais. http://portal.mec.gov.br/seb/arquivos/ pdf/Avalmat/guia_de_tecnologias_educacionais.pdf

MEC (2017). Edital de Convocação 01/2017- CGPLI Edital de Convocação Para o Processo de Inscrição e Avaliação de Obras Didáticas Para o Programa Nacional do Livro e do Material Didático PNLD 2019. https://www.fnde.gov.br/centrais-de-conteudos/ publicacoes/category/165-editais?download=11304:edital-pnld-2019-consolidado

MEC (2018a). Base Nacional Comum Curricular. http://basenacionalcomum.mec.gov. br/images/BNCC_EI_EF_110518_versaofinal_

MEC (2018b). Divulga resultado final da etapa de avaliação pedagógica do Programa Nacional do Livro e do Material Didático PNLD 2019 - Educação Infantil e Anos Iniciais do Ensino Fundamental - Edital 01/2017/CGPLI. Diário Oficial da União. http://www.imprensanacional.gov.br/web/guest/materia/-/asset_publisher/ Kujrw0TZC2Mb/content/id/37026711/do1-2018-08-16-portaria-n-30-de-15-deagosto-de-2018-37026402

MEC (2019). Guia Digital PNLD. https://pnld.nees.com.br/pnld_2019/escolha MEC (2020). PNLD - Estatística dos Dados do Programa do Livro. https://www.fnde. gov.br/programas/programas-do-livro/pnld/dados-estatisticos

Moreira, K., \& Rodrigues, E. (2014). O livro didático e as tecnologias de informação e comunicação na educação escolar: O livro didático sobreviverá às novas tecnologias?. EaD \& Tecnologias Digitais na Educação, 1(2), 57-68. http://ojs.ufgd.edu.br/index.php/ ead/article/view/3260 
Pessoa, R. R. (2009). O livro didático na perspectiva da formação de professores. Trabalhos em Linguística Aplicada, 48(1), 53-69. https://doi.org/10.1590/S010318132009000100005

Rosa, M. D., \& Mohr, A. (2016). Seleção e uso do livro didático: um estudo com professores de ciências na rede de ensino municipal de Florianópolis. Ensaio Pesquisa em Educação em Ciências (Belo Horizonte), 18(3), 97-115. https://doi.org/10.1590/198321172016180305

Rowan, C. (2014). 10 razões pelas quais dispositivos portáteis devem ser proibidos para crianças com idade inferior a 12 anos. https://antesqueelescrescam.com/2014/03/11/10razoes-para-se-proibir-tecnologia-para-criancas/comment-page-1/

Ruas, K. C. (2016). Processos de interação mediada pelas TDIC em curso a distância via web. (Dissertação de Mestrado Interdisciplinar em Educação, Linguagem e Tecnologias). Campus Anápolis, Universidade Estadual de Goiás.

Santos, W., \& Carneiro, M. H. (2013). Livro Didático de Ciências: Fonte de Informação ou Apostila de Exercícios?. Revista Contexto \& Educação, 21(76), 201-222. https://doi. org/10.21527/2179-1309.2006.76.201-222

Schmitt, C. da S., \& Domingues, M. J. C. de S. (2016). Estilos de aprendizagem: Um estudo comparativo. Avaliação: Revista da Avaliação da Educação Superior (Campinas), 21(2), 361-386. https://doi.org/10.1590/S1414-40772016000200004

Silva, R., \& Barbosa, A. (2016). Ensino de ciências e tecnologias digitais: Desafios e potencialidades. Ciclo Revista, 1(2). https://www.ifgoiano.edu.br/periodicos/index.php/ ciclo/article/view/218

Silva, I. M. M., Silva, A. P. T. B., Mota A. C., \& Calado E. F. N. (2017). Materiais Didáticos Dialógicos Para Ead: Conexões Com as Histórias em Quadrinhos. In XXIII Congresso Internacional ABED de Educação a Distância - Ciaed, (pp. 1-10). Recife-PE. http://www. abed.org.br/congresso2017/trabalhos/pdf/183.pdf

Silva, W., \& Kalhil, J. (2018). Tecnologias digitais no ensino de ciências: Reflexões e possibilidades na construção do conhecimento científico. Revista Brasileira de Educação em Ciências e Educação Matemática, 2(1), 77-91. https://doi.org/10.33238/ ReBECEM.2018.v.2.n.1.19155site.pdf

Soares, M. H. (2013). Jogos em Ensino de Química. Kelps.

Viveiro, A. A., \& Diniz, R. E. (2009). As atividades de campo no ensino de ciências: Reflexões a partir das perspectivas de um grupo de professores. In R. Nardi (Org.), Ensino de ciências e matemática, I: temas sobre a formação de professores [online] (pp. 27-42). São Paulo: Editora UNESP. http://iseo.com.br/wp-content/uploads/2015/05/022-Ensino-deci\%C3\%AAncias-e-matem\%C3\%A1tica-I-temas-sobre-a-forma\%C3\%A7\%C3\%A3ode-professores.-Nardi-Roberto.pdf 
Wesendonk, F. S., Rodrigues, L. Z., \& Terrazzan, E. A. (2011). Atividades Didáticas Experimentais em Livros Didáticos do PNLD para o Ensino de Biologia e Física. In VIII Encontro Nacional de Pesquisa em Educação em Ciências - ENPEC, (pp. 1-12). Campinas, SP. http://www.nutes.ufrj.br/abrapec/viiienpec/resumos/R1670-1.pdf

\author{
João Ferreira Sobrinho Junior \\ Universidade Federal de Goiás \\ Programa de Pós-Graduação em \\ Educação para Ciências e Matemática (PPGECM) \\ Goiânia, Goiás, Brasil \\ joffersoju07@hotmail.com \\ ${ }^{\oplus}$ Nyuara Araújo da Silva Mesquita \\ Universidade Federal de Goiás \\ Instituto de Química \\ Goiânia, Goiás, Brasil \\ nyuara2006@gmail.com
}

Editora Responsável

Stefannie Ibraim

Manifestação de Atenção às Boas Práticas Científicas e de Isenção de Interesse

Os autores declaram ter cuidado de aspectos éticos ao longo do desenvolvimento da pesquisa e não ter qualquer interesse concorrente ou relações pessoais que possam ter influenciado o trabalho relatado no texto. 